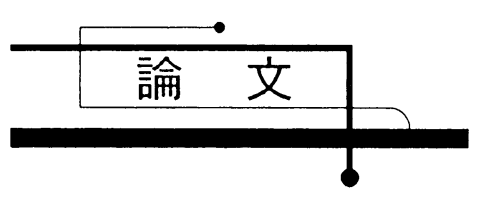

\title{
液滴列の衝突による微細孔への液体侵入*
}

\section{Liquid Infiltration into a Closed-End Hole by the Impingement of a Droplet Train}

\author{
山口えり $り^{* *}$ \\ YAMAGUCHI Eri
}

\author{
真 田 俊 之诺* \\ SANADA Toshiyuki
}

\begin{abstract}
Liquid infiltration is an important process for cleaning inside small size holes. However, it is difficult to infiltrate liquid into closed end holes having small diameter. Because the surface tension prevents the deformation of gas-liquid interface for entering the liquid. In this study, we observed the liquid infiltration process into a closed end hole by applying external pressure under two ways, i.e. gradual pressurization with a hand pump and impingement of a droplet train. As a result, it is found that the amount of dissolved air into liquid by applying pressure is small, and it has small effect for the liquid infiltration. In addition, it is also found that the high liquid infiltration rate can be achieved by applying a droplet train impact. The trapped bubbles inside the holes were ejected by repetition of droplet impingement. On the other hand, such the high liquid infiltration was not observed by the liquid column impact. Possible mechanisms of liquid infiltration by a droplet train impingement are discussed.
\end{abstract}

Keywords: Liquid infiltration, Closed end holes, Droplet train, Liquid column

\section{1. 緒 言}

様々な新規材料が導入される半導体製造工程 では、その複合污染を避けるためウェハを一枚ず つ洗浄する枚様式洗浄が一般的となった[1]。その 洗浄は一般的にウェット状態で行われる。表面で の付着不純物は、大気中では液体中と比べて大き なハマカー定数[2]を持ち、さらに毛管凝縮の影響 により高い付着力となるためである[3]。一方で枚 葉式では、限られた時間での洗浄が必要となり、 洗浄液の化学的作用のみならず、液滴衝突やブラ シなどの物理的作用が併用される $[1,4]$ 。半導体デ バイス製造等の微細で複雑な構造を有する表面 での洗浄工程は、まず液体 (洗浄液) をその構造 内へと浸漬させ、洗浄を行い、その後液体をアル コールへ置換し、最後に液体を乾燥させる。とこ ろが、これらの工程は経験的に行われており、そ の過程についての知見は限られている[5-7]。

先端が封じられた微細孔への液体侵入は、直径
が十分に大きい孔の場合には、孔の一部で液体が 侵入し他方で気体が上昇するため、孔を容易に液 体で満たすことができる。しかし、孔の直径がキ ヤピラリー長程度まで小さくなると、液体の侵入 は表面張力によって阻まれる[8]。先端が開いた管 の場合、表面張力が液体侵入のための駆動力とな る。一方で、先端が封じられている場合には、管 内部の気体の圧力による力が液体侵入を妨げる 向きに働くため、これに対抗するための外部圧力 が必要となる[9]。

本研究では、先端が封じられた孔を有するプレ ートへの液体侵入について調查する。まず夜体で 満たした容器内で段階的に圧力を印加し、圧力に よる液体侵入を行い、細管で行われた実験[9]との 比較を行う。次に、圧力の印加状態を実際の洗浄 工程に近づけるため、大気中で液滴列を衝突させ た場合の微細孔への液体侵入の様子を観察し、液 滴列の周波数による違いや、平板衝突時について

* 2016.11.14 受付

** 静岡大学大学院総合科学技術研究科工学専攻

*** 静岡大学学術院工学領域 $\bar{T} 432-8561$ 浜松市中区城北 3-5-1

TEL: (053)478-1605 FAX: (053)478-1605 E-mail: sanada.toshiyuki@shizuoka.ac.jp 
多数の報告がなされている液柱衝突[10-12]との 比較検討を行う。

\section{2. 実験方法および実験条件}

\section{1 液体中での圧力印加実験}

液体中で圧力を印加した場合の実験装置の概 略図を Fig. 1 に示す。耐圧容器を液体で満たし、 容器内部に固定された観察対象物への液体侵入 の様子を観察した。実験系全体を、ハンドポンプ （アサダ、テストポンプ TP50B）を用いて加圧し た。液体圧力は、圧力計（キーエンス、AP-13S） で測定し、レコーダー（日置電機、メモリハイコ ーダ 8870) で記録した。耐圧容器の上面と下面は ガラス空になっており、下面から反射板によって 光路を水平方向から垂直方向へ変更した光を当 て、上面から顕微鏡（Leica、Z16APO）を取り付 けた高速度カメラ（ノビテック、Phantom M310） で液体侵入の様子を観察した。

液体の圧力印加方法として、加圧と減圧の操作 計 3 回を約 20 分かけてゆっくりと行う場合と、 約 10 秒で急激に行う場合の 2 方法で行った。ど ちらの場合も圧力をゲージ圧で $0 \mathrm{kPa}$ から 700 $\mathrm{kPa}$ 程度まで変化させた。ゆっくりと加圧する場 合には、 $100 \mathrm{kPa}$ 毎に液体侵入の水位を観察した。 液体として超純水（ミリポア、Direct-Q 3UV）を 使用した。

観察対象物の概略図を Fig. 2 に示す。厚さ 10 $\mathrm{mm}$ の石英ガラス板に直径 $1.0 \mathrm{~mm}$ の貫通孔を開 け、観察のため側面を鏡面仕上げしたプレートを 使用した。これをシリコーンゴムシートで封じる ことで閉じた構造とした。孔のアスペクト比は 10 である。液体侵入の評価は、液体侵入長さ $h$ を孔 深さ $h_{0}$ で除した液体侵入率 $h_{w}$ を用いて行った。 また $\theta / 2$ 法により測定した実験サンプルの接触角 は43 度であった。

\section{2 液柱および液滴列衝突実験}

大気中での液滴列および液柱の衝突実験の概 略図を Fig. 3 に示す。微細管 (外径 $1 / 16$ inch、内 径 $1.4 \mathrm{~mm}$ 、PEEK 製）から生成された液柱および 液滴列を Fig. 2 に示した観察対象物へ衝突させ、 液体侵入の様子を観察した。観察対象物は x-y ス テージ上に固定し、ノズル直下へトラバースさせ ることで、液柱および液滴列を衝突させた。液体 侵入の様子はマクロレンズ（Nikon、Micro-Nikkor $105 \mathrm{~mm} \mathrm{f} / 2.8$ ) を取り付けた高速度カメラを用い

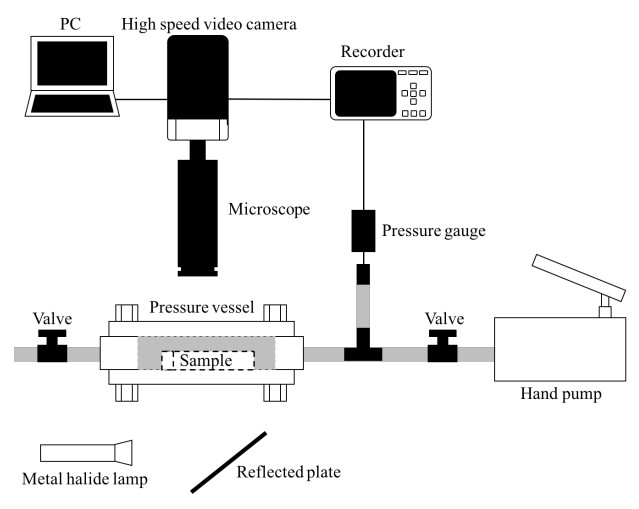

Fig. 1 Schematic of experimental setup for gradual pressurization. Test sample was fixed in the pressure vessel that was pressurized by a hand pump. Liquid infiltration process was visualized using a high speed video camera with microscope.

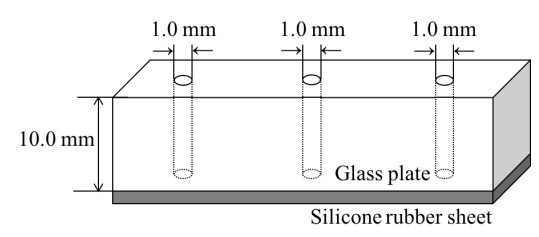

Fig. 2 Test sample. Three holes that diameter was $1 \mathrm{~mm}$ were drilled on glass plate and silicone rubber sheet was attached to close the hole end.

て撮影した。液体はタンク内の空気を加圧するこ とでノズルへ圧送し、ノズル手前のバルブによっ て流量を調節した。加圧タンクは 2 つ用意し、上 流側のタンクには空気のみを、下流側のタンクに は液体を入れた。これにより、コンプレッサー稼 働による流量変化を緩和できる。液体は同様に超 純水を使用した。

ノズルから生成される液体は、ノズルに近い部 分で液柱、その後 Rayleigh-Plateau 不安定性によ り液滴列となる。そのため、ノズルと観察対象物 との距離を変更することで液柱および液滴列の 衝突を実現した。この場合の液滴列の生成周波数 は 500 $1250 \mathrm{~Hz}$ 程度であった。また、微細管先 端で液滴が生成される場合[13]には、生成される 液滴列の周波数が大幅に減少する。この条件を利 
用して低周波数液滴列（約 $4 \mathrm{~Hz}$ ) を実現し、比較 検討した。なお加圧タンク内の圧力は $0.1 \sim 0.3$ $\mathrm{MPa}$ とした。液柱および液滴列の衝突速度はおよ そ $2.5 \mathrm{~m} / \mathrm{s}$ であり、低周波数の場合は $1.1 \mathrm{~m} / \mathrm{s}$ であ った。高周波数液滴列と液柱の場合には約 3 秒間 衝突させ、液体侵入率 $h_{w}$ を求めた。また低周波 数液滴列の場合には約 20 分間衝突させ、衝突液 滴数を揃え比較した。なお液滴列衝突時の $h_{w}$ は 細孔内の気体と液体の比率で評価した。

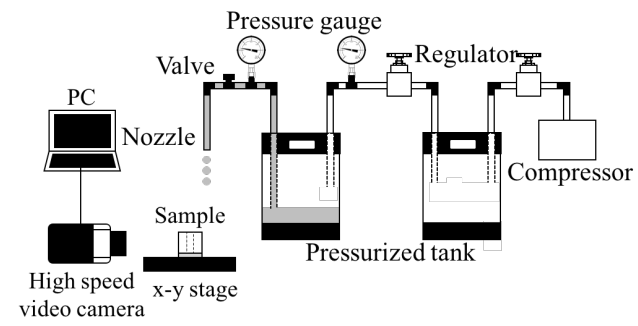

Fig. 3 Schematic of experimental setup for impingement of a droplet train and liquid column. A droplet train and liquid column were formed by changing the distance between nozzle and sample.

\section{3. 実験結果と考察}

\section{1 液体中での加圧による液体侵入}

まず、耐圧容器を用いて液体中でゆっくりと加 圧した場合の細孔への液体侵入の様子を観察し、 細管[9]との比較を行った。Fig. 4 に印加した圧力 $P$ と $h_{w}$ の関係を示す。Fig. 4(a) は 1 回目の加圧 による結果を、Fig.4(b)および(c)はそれぞれ 2 回 目、3 回目の結果を示す。ここで、Fig. 4(c)にお いて*で表された值は、3度の加圧の後に減圧し、 最終的な $h_{w}$ を示しており、 $h_{w}=0.20$ であった。

Fig. 4 の実線は等温過程における理想気体の状態 方程式から見積もった值である。Fig. 4 より、加 圧回数の増加に伴い $h_{w}$ がわずかに見積もり值を 上回ることが分かる。これは加圧による気体の溶 解を示している。しかし、700 kPa といら高圧を 印加しているにも関わらず、細管の場合と同様に 完全な液体侵入に至らなかった。

10 秒間で瞬間的に 3 回加圧を行った実験も、 細管と同様の結果で、等温過程を仮定した変化と ほぼ一致し、溶解量は極僅かであったためここで は省略する。しかしこの瞬間的加圧実験において、
細管では見られなかった現象が観察されたため 3.3 節にて議論を行う。このように水中で高圧を

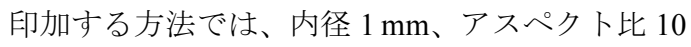
の孔に完全な液体侵入を果たすことは困難であ ることが確認できた。

\section{2 液柱および液滴列衝突実験}

次に、大気中で液柱および液滴列を衝突させた 場合の液体侵入の様子を観察し、液柱と液滴列の 結果を比較した。Fig. 5(a)に液柱衝突の観察結果 を、液体侵入開始時刻を $t=0 \mathrm{~s}$ とし $t=0.5 \mathrm{~s}$ から $t=2.5 \mathrm{~s}$ までを 0.5 秒間隔で示している。Fig. 5(b) に衝突終了後の結果を示す。また、同様に Fig. 6(a)に高周波数の液滴列衝突の観察結果を、Fig. 6(b)に衝突後の結果を示す。これらの図から、衝 突終了後つまり、衝突圧が印加されていない状態 でも衝突時と同程度の侵入率を維持しているこ とがわかる。これより、水中での加圧実験におけ る液体侵入は気体の圧縮によるものであったが、 液柱および液滴列衝突の場合、侵入液体と同体積 の気体排出によるものであることが分かる。また、 衝突速度は同じであるにも関わらず、最終的な $h_{w}$ は液柱に比べて液滴列の場合に極めて高い。

Fig. 5(a)、Fig. 6(a)より、液柱衝突の場合、一定 時間が経過しても $h_{w}$ は増加しないが、液滴列衝 突の場合、時間が経つにつれて侵入率が向上する ことが分かる。Fig. 7 に液滴列衝突時の時間 $t$ と 液体侵入率 $h_{w}$ の関係を示す。ここでは、典型的 な 2 ケースについて示している。この図から、 $h_{w}$ が振動しながら増加する様子が確認できる。この 侵入率の振動は、細孔内に形成された気柱が膨張 および収縮によって、孔内部の空気割合が変動す ることを示している。以上に示すように、高い $h_{w}$ を得るためには、孔内部の気体の分裂による気柱 （気泡）生成と、その振動による排出が必要であ ることが示された。

次に低周波数液滴列において 20 分間の衝突試 験を行ったが、ほとんど液体は侵入せず、最終的 な侵入率は $h_{w}=0.08$ であった。詳細は次節にて 検討を行う。

\section{3 考察および予想される気体排出メカニズム}

微細孔を液体で満たすためには、初期に微細孔 内部に存在する気体を排出しなければならない。 そこで、気泡の排出メカニズムについて考察を行 う。液滴列の周波数を $1000 \mathrm{~Hz}$ 程度と $4 \mathrm{~Hz}$ の 2 つに設定して実験を行い、高周波数の場合は高い 

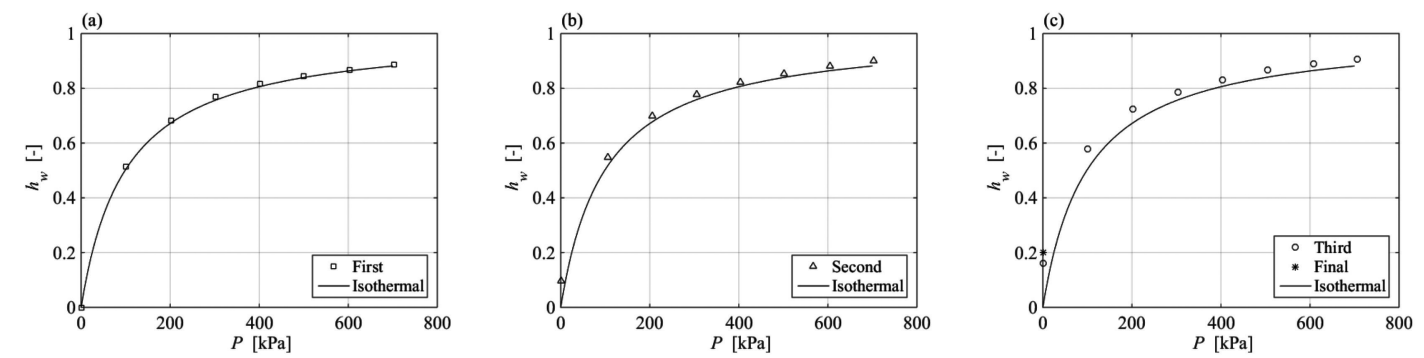

Fig. 4 Relationship between applied pressure $P$ and liquid infiltration rate $h_{w}$ in (a) first compression, (b) second compression, (c) third compression and after the pressure release. Only the partial liquid infiltration into the hole owing to gas compression was achieved with the help of the significantly high external gas pressure. Limited amount of the gas was dissolved into the liquid.

侵入率を得たが、低周波数の場合、ほとんど液体 侵入は起こらなかった。一方、低周波数の液滴列 が衝突した際には、Fig.5(b)に示すような細孔内 の気液界面が、液滴衝突後に僅かに振動した。こ の気液界面の変位 $z \mathrm{~mm}$ の時間変化の例を Fig. 8 に示す。完全に同一形状の液滴が衝突していない ためか、この振動は衝突する液滴ごとに若干変化 した。なお、 $\mathrm{z}$ の基準は振動していない時の気液 界面の位置であり、重力方向の変位を負の值で示 す。Fig. 8 より、単一液滴が衝突することによっ て引き起こされた気体の振動は、いずれの場合も およそ $15 \mathrm{~ms}$ 程度で減衰した。この振動は、液体 が細管内で上下運動する際の粘性散逸により減 衰したと考える。一方で、高周波数の液滴列は、 $15 \mathrm{~ms}$ より短い周期で次の液滴が衝突している。 連続して液滴が衝突することで、気体振動が複雑 な強制振動となったことが液体侵入への 1 つの 重要なプロセスだと予想する。

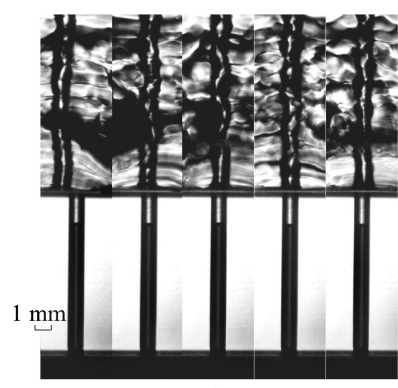

(a)

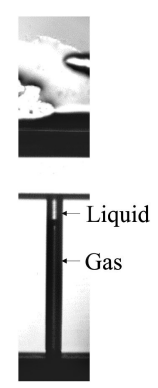

(b)
Fig. 5 Infiltration by liquid column impact, (a) time interval is $0.5 \mathrm{~s}$, (b) final liquid infiltration. Final liquid infiltration $h_{w}=0.13$.

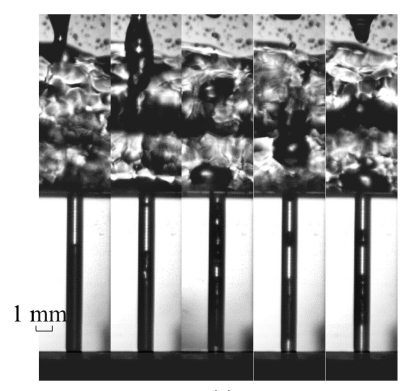

(a)

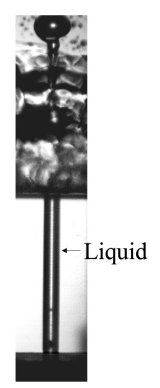

(b)
Fig. 6 Infiltration by a droplet train impingement, (a) time interval is $0.5 \mathrm{~s}$, (b) final liquid infiltration. High liquid infiltration rate $\left(h_{w}=\right.$ 0.87) compared to the liquid column was achieved.

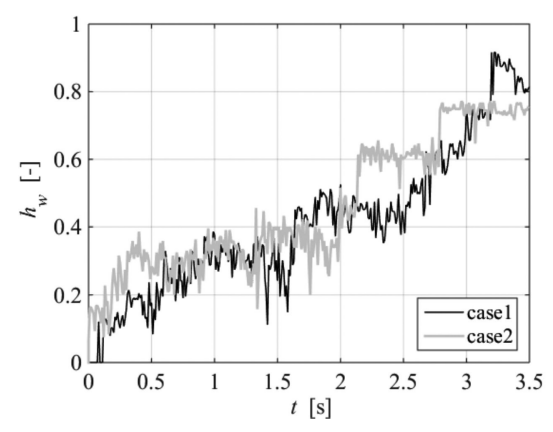

Fig. 7 Time change of $h_{w}$ during a droplet train impingement. High liquid infiltration rate was achieved after several second impingement. 


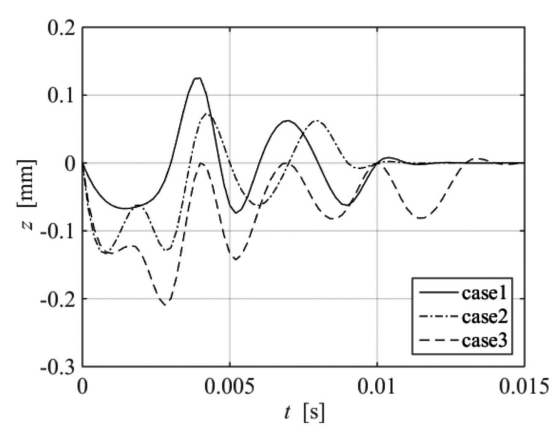

Fig. 8 Gas-liquid interface oscillation owing to low frequency (about $4 \mathrm{~Hz}$ ) droplet impingement. The oscillation was damped in about $15 \mathrm{~ms}$.

次に、Fig. 9 およびFig. 10 には、細孔内に液 体に挟まれた気泡が生成された直後と、その気泡 が排出される直前の時系列を示寸。図の赤い矢印 は、液滴が衝突した瞬間を表している。Fig. 9 で は、気泡が下方に移動し始めるタイミングで液滴 が衝突している。一方で、Fig. 10 では、気泡が上 方へ移動している時に液滴が衝突する場合があ り、その後気泡の上下運動の中心が上方へと移動 している。本実験では液滴列の周波数を完全に制
御していないが、非周期的な液滴の衝突直後に $h_{w}$ の大きな変化が観察された。非周期的な液滴の衝 突は、液滴列の衝突によって振動していた気液界 面を変化させ、その結果気液界面において何らか の現象が生じたと考える。例えば振動ポアゾイユ 流れにおいては、その Reynolds 数と Womersley 数 によって壁面近傍で逆流が生じる[14]。振動する 気液界面ではその Capillary 波によって液滴が形 成される場合があり[15]、このような流れ場の変 化よって振動する気液界面から液滴が生成され るなどの理由によって気泡が分裂した可能性が ある。

液柱衝突の場合にも、気液界面の振動を観察し た。その様子と $h_{w}$ の時間変化を Fig. 11 と Fig. 12 にそれぞれ示す。この変位は極めて小さく、Fig. 7 に示される液滴列衝突の場合とは異なる。その 理由として発生圧力の非定常性が挙げられる。一 般的に、液柱や液滴が衝突した場合にはその動圧 程度の圧力が作用すると予測でき、その值を衝突 流速より見積もると $3.0 \mathrm{kPa}$ 程度である。Fig. 12 に示寸ように、夜柱衝突時の時間平均した $h_{w}$ は、 $h_{w}=0.19$ であり、衝突後には $h_{w}=0.13$ であるこ とから、この差に当たる長さ $0.66 \mathrm{~mm}$ 分の気体が

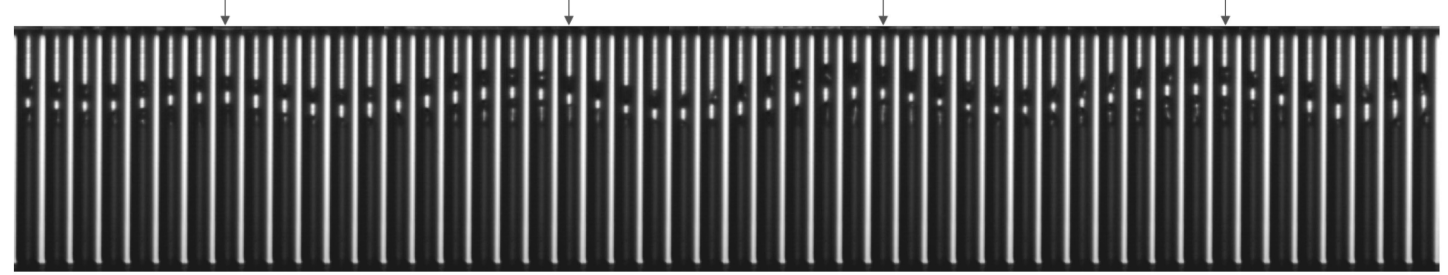

Fig. 9 Bubble formation during a droplet train impingement. Black color indicates gas phase. Height of each image is $10 \mathrm{~mm}$. Red arrows indicate the timing of droplet impact. Time interval of each image is $2 \mathrm{~ms}$. Gas-liquid interface oscillation owing to droplets impact was observed.

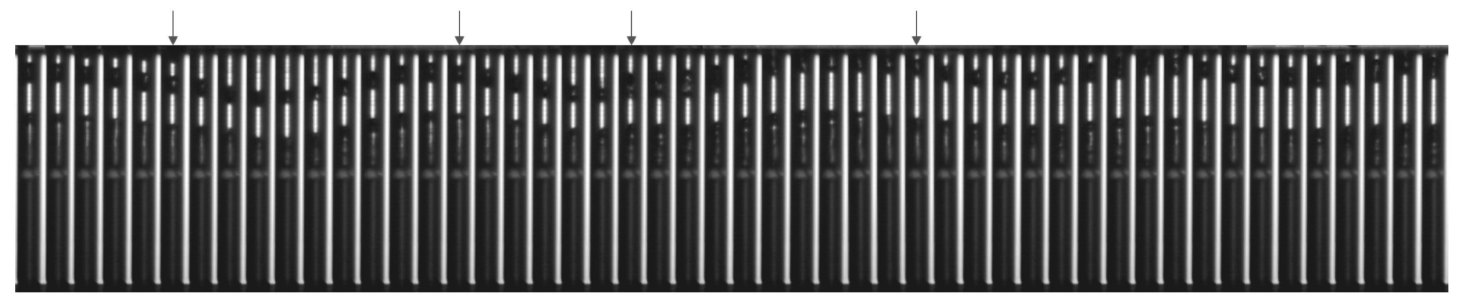

Fig. 10 Gas discharge during a droplet train impingement. Black color indicates gas phase. Height of each image is $10 \mathrm{~mm}$. Red arrows indicate the timing of droplet impact. Time interval of each image is 2 ms. 


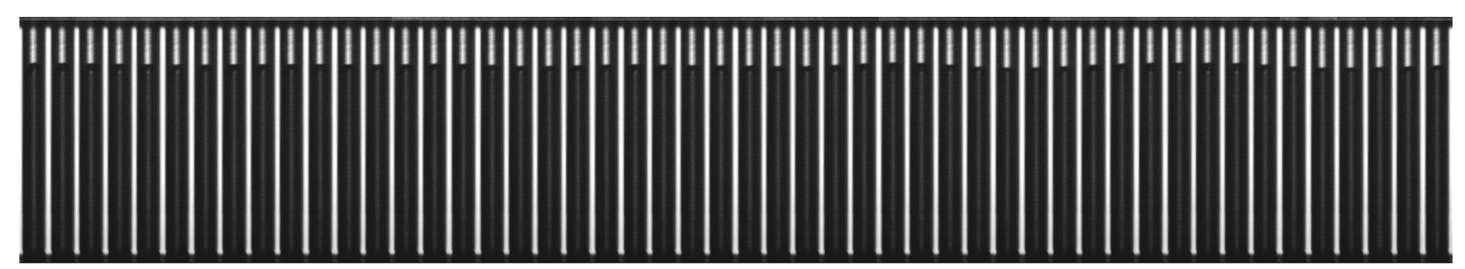

Fig. 11 Gas-liquid interface oscillation during liquid column impact. Black color indicates gas phase.

Height of each image is $10 \mathrm{~mm}$. Time interval of each image is $2 \mathrm{~ms}$. Small gas-liquid interface oscillation during liquid column was observed.

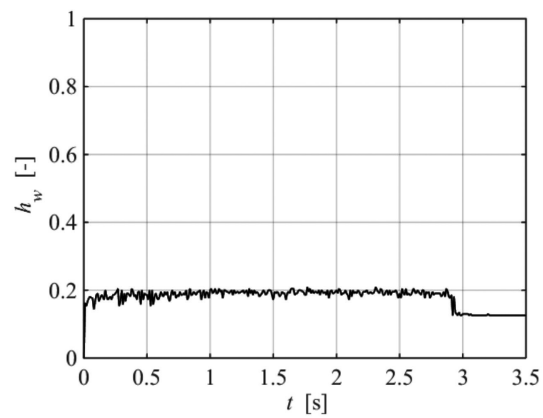

Fig. 12 Time change of $h_{w}$ during liquid column impingement.

液柱衝突压によって圧縮されている。等温過程に おける理想気体の状態方程式からその圧力を算 出すると $8.2 \mathrm{kPa}$ となり、見積もりとオーダーが 一致する。つまり、夜柱でも界面振動はあったが、 そもそも圧力がほぼ定常的に印加されており、そ の変位は非常に小さかった。この差が大きな侵入 率の違いにつながったと考える。上記で議論した
内容について、各現象を压力印加状態で分類し整 理した表を Table 1 に示す。

次に液滴衝突による圧力变化によって移動す る、固気液三相界面である接触線の移動について 検討する。耐圧容器を用い瞬間的に加圧および減 压を行った実験にて、加圧時に気柱が分裂する様 子が観察された。その様子を Fig. 13(a)に示す。 また、減圧時には、気柱の分裂により生成された 気泡が排出された。その様子を Fig. 13(b)に示す。 これらの画像の時間間隔は $25 \mathrm{~ms}$ である。図に示 されるように、加圧時にピン止めが発生し、気泡 が残り、その気泡が収縮する現象が観察された。 一方減压時には、このピン止めされた気泡の成長 と、压縮された気柱の膨張が起こり、その液体の 排出によって気泡が排出されている。この例のよ うに、高速な接触線の移動に伴う、Wetting Failure などの現象も気柱の分裂や気泡生成に関連して いる可能性がある。また減圧時には実験装置内 様々な位置より気泡が発泡するが、その位置は事 前にはほぼ予測不可能である。例えば、この発泡

Table 1 Categorization of phenomena based on the condition of the pressurization.

\begin{tabular}{|c|c|c|}
\hline Pressurization conditions & Phenomena & Related figures and references \\
\hline \multirow{2}{*}{ Constant } & Gradual pressurization with hand pump & $\begin{array}{c}\text { Fig. 4 (a closed end hole) } \\
{[9] \text { (closed end tubes) }}\end{array}$ \\
\cline { 2 - 3 } & Liquid column impingement & Fig. 5, Fig. 11, Fig. 12 \\
\hline \multirow{2}{*}{\begin{tabular}{c} 
Periodic variation \\
\cline { 2 - 3 }
\end{tabular}} & $\begin{array}{c}\text { Droplets impingement } \\
\text { (Low frequency) }\end{array}$ \\
\hline $\begin{array}{c}\text { Non - periodic } \\
\text { variation }\end{array}$ & $\begin{array}{c}\text { A droplet train impingement } \\
\text { (High frequency) }\end{array}$ & Fig. 9 \\
\hline
\end{tabular}


(a)

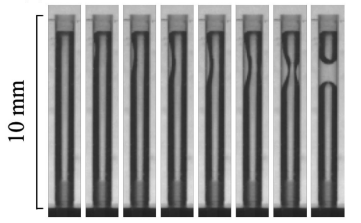

(b)

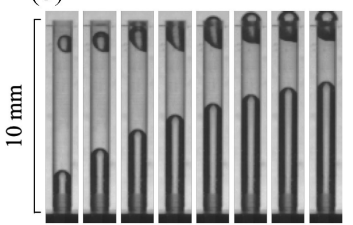

Fig. 13 Bubble breakup and discharge, (a) instantaneous pressurization process, (b) instantaneous depressurization process.

が細孔内で起こったとすれば、発泡が気柱の分離 を引き起こし、そして細孔内での気泡生成へ関連 すると予想する。

また Fig. 14 に示される現象も液滴侵入の予想 メカニズムに関連していると思われる。例えば Fig. 14(a)は Fig. 4 で示した外部圧力による液体 侵入の一例を示し、Fig. 14(a)(1)は加圧前、Fig. 14(a)(2)は加圧時、Fig. 14(a)(3)は減圧後を示す。 Fig. 14(a)(1)と(3)では一度液体侵入した領域の光 の透過状態が明らかに異なる。これは液体の侵入 によって極めて薄い夜膜が形成したと予想し、こ の液膜は前述の接触線の移動に大きな影響を及 ぼすことが予想される。また Fig. 14(b)は細孔を 塞がずに、開放状態で液滴列を衝突させた結果で ある。図のように多くの気泡が観察される。これ は液滴衝突時に発生した巻き込み気泡である。こ のように液滴列の衝突による高い液体侵入率の 観察結果には複雑な現象が関係しており、今後そ の詳細を調査する予定である。

(a)

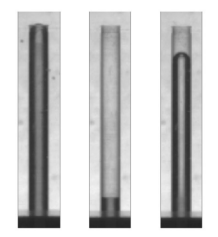

(1) (2) (3)

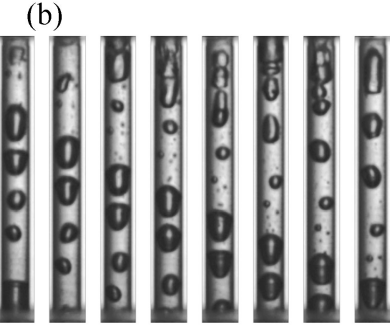

Fig. 14 Other hypothesis of liquid infiltration. (a) liquid film formation, (1) before the experiment, (2) compression, (3) release pressure, (b) bubble formation by a droplet train impingement into a through hole.

\section{4. 結 言}

本研究では、先端を封じた細孔への液体侵入特 性について、超純水で満たされた容器内で段階的 に加压を行った場合と大気中で液柱および液滴 列を衝突させた場合について調査した。容器内で の段階的加压実験では、孔内部の空気溶解量は少 なく、空気の圧縮によって液体は侵入した。その ため圧力の開放と共に侵入率は大きく減少した。 一方で、高周波数の液滴列を衝突させた場合には、 衝突により内部の気体を排出することができ、数 秒のうちに孔を超純水で満たすことができた。し かし液柱や低周波数の液滴列衝突ではそのよう な液体侵入は確認されなかった。

\section{謝 辞}

本研究の一部は、JSPS 科研費 JP23760152 の支 援を得た。また実験の一部では静岡大学大学院生 の野崎紘史氏、村木駿介氏の協力を得た。さらに 查読者の一人には侵入メカニズムに関する新た な知見を頂いた。ここに記して謝意を示す。

\section{Nomenclature}

$h \quad$ : water level

$h_{0} \quad$ : depth of hole

$h_{w} \quad:$ liquid infiltration rate

$P \quad$ : pressure

$t \quad$ : time

$z \quad$ : coordinate

[mm] [mm]

$[\mathrm{kPa}]$

\section{参考文献}

[1] Hattori, T., Use of Multiphase Flows in LeadingEdge Semiconductor-Surface Cleaning, Japanese Journal of Multiphase Flow, Vol. 24(1), 13-20 (2010).

[2] Israelachvili. J. N., Intermolecular and Surface Forces, 253-255, Academic Press (2011).

[3] Sanada, T. and Watanabe, M., Physical Fluid Cleaning (1) General Concepts and Adhesion of Fine Particles, The Chemical Times, Vol. 226(2), 17-23 (2015).

[4] Sanada, T. and Watanabe, M., Physical Fluid Cleaning (3) Jet, Brush, and Other Topics, The Chemical Times, Vol. 238(4), 16-21 (2015).

[5] Olim, M., Liquid-phase Processing of Hydrophilic Features on a Silicon Wafer, Journal of Electrochemical Society, Vol. 144(12), 43314335 (1997).

[6] Ota, K. and Tsutsumi, A., Liquid Infiltration Mechanism for Cleaning in Deep Microholes, ECS Transactions, Vol. 11(2), 299-306 (2007).

[7] Spuller, M. T. and Hess, D. W., Incomplete 
Wetting of Nanoscale Thin-film Structures, Journal of Electrochemical Society, Vol. 150(8), G476-G480 (2003).

[8] De Gennes, P.-G., Brochard-Wyart, F. and Quéré, D. (translated by Okumura, K.), Capillarity and Wetting Phenomena: Drops, Bubbles, Pearls, Waves, Yoshioka Shoten (2003).

[9] Sanada, T., Nozaki, H. and Watanabe, M., Gas Compression and Dissolution in Closed End Tubes by Applying Pressure (Liquid Infiltration Characteristics into Fine Structure by Pressure), Transactions of the JSME, Vol. 82 No.838 (2016).

[10] Bush, J. W. M. and Aristoff, J. M., The Influence of Surface Tension on the Circular Hydraulic Jump, J. Fluid Mech., Vol. 489, 229-238 (2003).

[11] Passandideh-Fard, M., Teymourtash, A. R. and Khavari, M., Numerical Study of Circular Hydraulic Jump Using Volume-of-Fluid Method,
Journal of Fluids Engineering, Vol. 133, 011401 (2011).

[12] Brechet, Y., Neda, Z., On the Circular Hydraulic Jump, Am, J. Phys. Vol. 67(8), 723-731 (1999).

[13] Tachibana, J. and Sanada, T., Control of Droplet Generation with Airflow and Capillary Tube (Transition Condition for Droplet to Liquid Column Formation at the Capillary Tip), Japanese Journal of Multiphase Flow, Vol. 29(1), 42-49 (2015)

[14] Ku, D. N., Blood Flow in Arteries, Annu. Rev. Fluid Mech., Vol. 29, 399-434 (1997).

[15] Rodriguez-Rodriguez, J., Sevilla, A., MartinezBazan, C. and Gordillo, J. M., Generation of Microbubbles with Applications to Industry and Medicine, Annu. Rev. Fluid Mech., vol. 47, 405429 (2015). 